\title{
Effect of aluminized reflective hutch covers on calf health and performance
}

\author{
D. Manriquez, ${ }^{*}$ H. Valenzuela,† S. Paudyal, ${ }^{*}$ A. Velasquez, ${ }^{*}$ and P. J. Pinedo*1 \\ *Department of Animal Sciences, Colorado State University, Fort Collins 80523-1171 \\ †Universidad Santo Tomas, Santiago, Chile 8370003
}

\section{ABSTRACT}

The effect of polyethylene hutches wrapped in aluminized reflective covers (ARC) on health and performance of pre-weaned Holstein heifers during summer was evaluated. Ambient and hutch temperature and temperature-humidity index (THI) were also assessed. The study was conducted from June to October 2016 where temperature, humidity, and THI ranged from -1.3 to $38.4^{\circ} \mathrm{C}, 9.8$ to $99.7 \%$, and 33.6 to 81.1 units, respectively. Heifers enrolled at $1 \mathrm{~d}$ of life and housed in individual polyethylene hutches with (covered) or without (control) ARC were monitored until $60 \mathrm{~d}$ of life in 2 study groups (SG1, $\mathrm{n}=94$, monitored from June to September; and SG2, $\mathrm{n}=101$, monitored from August to October 2016). Calves were assessed twice per week for health status, behavior, rectal temperature, and respiratory rate. Similarly, hutch inner wall and sand bedding temperatures were determined for comparison between covered and control hutches housing calves. Four empty hutches per treatment group were continuously monitored for temperature and THI. The odds (95\% confidence interval) of presenting diarrhea were $1.30(1.01-1.60)$ times greater for calves housed in covered hutches than for those in the control group. Similarly, the odds of an abnormal ear score were 1.40 (1.03-2.00) times greater for calves in covered hutches compared with calves in control hutches. The odds of nasal discharge, eye discharge, and clinical dehydration did not differ between treatment groups. Rectal temperatures and respiratory rates were also similar in both groups. No differences were found in average daily gain between calves housed in covered and control hutches. Calf location determined at a fixed time during the day (starting at $1200 \mathrm{~h}$ ) was associated with the use of ARC. The odds of remaining inside the hutch were 1.33 (1.03-1.70) times greater for calves housed in control compared with covered hutches. Overall, the average of hutch interior temperature was higher in

Received April 18, 2017.

Accepted October 26, 2017.

${ }^{1}$ Corresponding author: pablo.pinedo@colostate.edu covered compared with control hutches in both studies (SG1, $23.2 \pm 0.06$ vs. $22.8 \pm 0.06^{\circ} \mathrm{C}$; SG2, 17.1 \pm 0.07 vs. $16.9 \pm 0.07^{\circ} \mathrm{C}$ ). Hutch THI was higher in covered empty hutches compared with control hutches in both study groups (SG1: $68.6 \pm 0.06$ vs. $67.6 \pm$ $0.06^{\circ} \mathrm{C}$; SG2: $60.2 \pm 0.08$ vs. $\left.59.6 \pm 0.08^{\circ} \mathrm{C}\right)$. Average temperature (measured at $1200 \mathrm{~h}$ ) of the inner surface of the hutch wall was lower in covered compared with control hutches by $1^{\circ} \mathrm{C}\left(24.4 \pm 0.13\right.$ vs. $\left.25.4 \pm 0.13^{\circ} \mathrm{C}\right)$, whereas the temperature of the sand bedding did not differ between groups. Our results suggest that the use of ARC did not generate a hutch microclimate that resulted in significant improvements on health and performance of pre-weaned dairy calves under these specific study settings.

Key words: heat stress, aluminized cover, calf

\section{INTRODUCTION}

Calf rearing is a complex constituent of dairy systems, where adequate growth, health, and well-being are critical components (Windeyer et al., 2014). In extensive areas of the United States, calves are challenged by extreme environmental conditions occurring during the hot season, resulting in reduced weight gain and increased morbidity and mortality (Roland et al., 2016). During summer, calves are exposed to thermic stress, defined as a change in the environment causing an alteration in body temperature that is not entirely compensated by thermoregulatory mechanisms (IUPS, 2001). The adverse effects of extreme heat begin before birth, during the periconceptional period and continue until late gestation, where heat-stressed dams produce offspring with lower milk yield during their first lactation, reduced survival, and impaired immunity and metabolism (Carroll et al., 2012; Brown et al., 2016; Guo et al., 2016; Roland et al., 2016).

The association between the magnitude of thermic stress and temperature-humidity index (THI) has been explored in lactating cows (Johnson et al., 1963; Bohmanova et al., 2007). In adult Holstein cows, critical THI values associated with milk yield decline ranged from 64 to 76 (Igono et al., 1992; West, 2003; Bohmanova et al., 2007). Although index values below 72 are generally 
identified as within the comfort zone (Armstrong, 1994; Bohmanova et al., 2007), lower THI thresholds have been proposed in recent reports (Schüller et al., 2017). Nonetheless, reference THI values associated with the performance of pre-weaned dairy calves are not well established.

In growing calves, body temperature regulation mechanisms are immature (NRC, 2001), resulting in higher susceptibility to changes in ambient conditions (Bateman et al., 2012). Consequently, heat stress may affect behavior, DMI, ADG, rectal temperature, respiratory rate, and disease frequency and survival (Sims et al., 2015; Peña et al., 2016; Yazdi et al., 2016). To address this concern, multiple housing strategies to improve calf cooling by creating more moderate housing microclimates have been evaluated (Spain and Spiers, 1996; Hill et al., 2011; Carter et al., 2014).

Recently, the use of sunlight reflective technology to reduce polyethylene hutch interior temperatures has been proposed (Binion et al., 2014; Carter et al., 2014; Friend et al., 2014). A recent report showed a decrease of about $4^{\circ} \mathrm{C}$ inside polyethylene hutches, when aluminized reflective hutch covers (ARC) were evaluated in dairies in central Texas for a total of $21 \mathrm{~d}$ of data collection, during late September and August (Binion et al., 2014). However, to the authors' knowledge, no evaluations have been performed during the entire preweaning period in commercial calf rearing operations assessing the effectiveness of the expected temperature reduction on improving calf health and performance.

Considering previous reports, our hypothesis was that the expected change in temperature due to sunlight reflection provided by ARC on polyethylene hutches would indirectly have an effect on the health and performance of pre-weaned dairy calves under hot conditions. Furthermore, resulting lower temperatures would alter calf behavior during the hottest periods of the day. Consequently, our objective was to evaluate the effect of ARC applied on polyethylene hutches on health and performance of pre-weaned dairy calves during the hot season in Northern Colorado, where summer temperatures can exceed $37^{\circ} \mathrm{C}$ (Colorado Climate Center, 2017). Additionally, the effects of ARC on hutch temperature and THI were evaluated.

\section{MATERIALS AND METHODS}

\section{Study Population and Calf Management}

All the animal-related procedures in this study were reviewed and approved by the Institutional Animal Care and Use Committee at Colorado State University (protocol ID: 16-6704AA). This research was conducted from June to October (2016) in a large dairy calf rearing facility, part of a dairy under certified organic management, located in Colorado. Pre-weaned calves were maintained in a total area of approximately $174,000 \mathrm{~m}^{2}$ and housed in polyethylene hutches (AgriPlastics, Stoney Creek, ON, Canada) exposed to direct sunlight. Walls built with straw square bales (3 m high) were installed on the perimeter of the calf rearing area (Figure 1).

Calves were immediately separated from the dam at birth. During the first hour of life had their navel dipped into an iodine $7 \%$ solution and were fed $2.8 \mathrm{~L}$ of colostrum warmed to $37^{\circ} \mathrm{C}$. Colostrum feeding was repeated at 3 and $8 \mathrm{~h}$ of life in the maternity facility. The colostrum globulin was determined by use of a colostrometer (Fleenor and Stott, 1980). The colostrum fed to calves had at least $52 \mathrm{mg} / \mathrm{mL}$ of globulin.

Within the first day of life, calves were transferred to the calf rearing facilities and housed individually in polyethylene hutches (inside dimensions: $201 \mathrm{~cm}$ length $\times 113 \mathrm{~cm}$ wide $\times 127 \mathrm{~cm}$ height). A front yard of 2.25 $\mathrm{m}^{2}$ enclosed by a galvanized welded wire fence and sand bedding was provided. Subsequently, calves received $3.8 \mathrm{~L}$ of colostrum fed in a 10-h interval 4 times. At $4 \mathrm{~d}$ of life, calves had access to small amounts of an organic certified calf starter (16\% Organic Calf Starter, Feedex Companies, LLC, South Hutchinson, KS) that increased according to intake up to 1.8 to $2.3 \mathrm{~kg} /$ animal per day until $56 \mathrm{~d}$ of life. A description of this product is presented in Table 1.

Starting at $4 \mathrm{~d}$ of life, calves received $2.5 \mathrm{~L}$ of pasteurized milk every $12 \mathrm{~h}$ until $14 \mathrm{~d}$ of life. From d 15 until d 49, calves received $3 \mathrm{~L}$ of milk every $8 \mathrm{~h}$. At 50 $\mathrm{d}$ of life, milk was fed only in the mornings and at $65 \mathrm{~d}$ of life, calves were weaned. Water was provided from d 1 in a plastic bucket $(8 \mathrm{~L})$ filled twice per day.

Dehorning was performed before $30 \mathrm{~d}$ of life using electrical cauterization under local anesthesia with veterinary supervision. The vaccination protocol included intranasal Inforce 3 (infectious bovine rhinotracheitis, parainfluenza-3, bovine respiratory syncytial virus; Zoetis, Florham Park, NJ) at 1 d of life, Ultrabac 8 (Clostridium chauvoei, Clostridium septicum, Clostridium hemoylticum, Clostridium novyi, Clostridium sordelli, and Clostridium perfringens type B, C, and D; Zoetis) at $21 \mathrm{~d}$ of life, Spirovac L5 (Leptospira canicola, Leptospira grippotyphosa, Leptospira hardjo, Leptospira icterohemorrhagiae, and Leptospira pomona bacterin; Zoetis) plus a booster of Inforce 3 and Ultrabac 8 at $42 \mathrm{~d}$ of life.

In addition to health assessment by the authors, calf health monitoring was performed daily by farm personnel. Calves needing antimicrobial therapy or other drugs not allowed in organic dairy systems were sent to a conventional calf ranch for prompt treatment. 


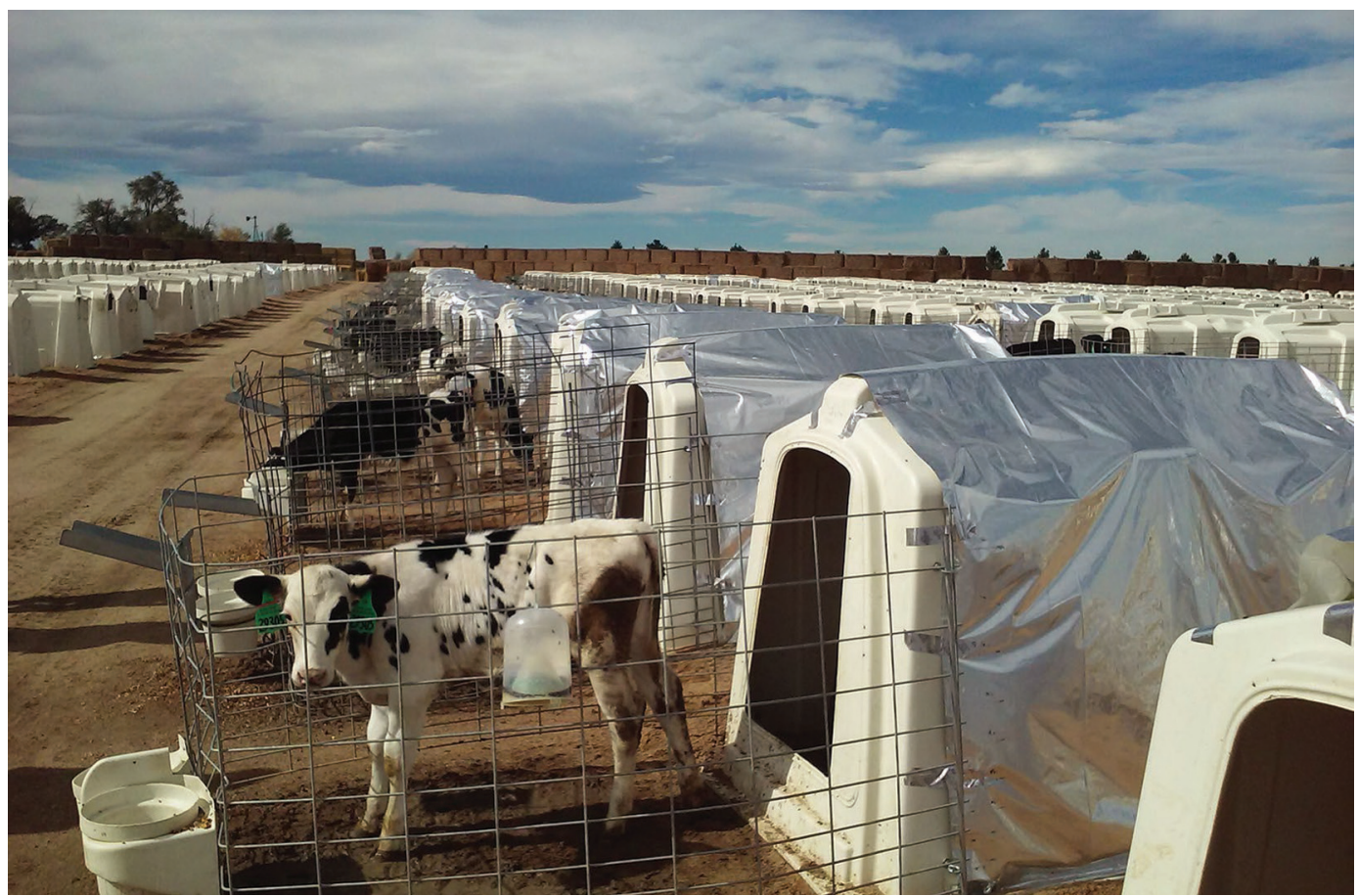

Figure 1. Overview of polyethylene hutches with (covered) or without (control) aluminized reflective covers located in contiguous blocks of 25 in 2 parallel lines. Color version available online.

\section{Experimental Procedures}

Two study periods were included in this research: study group (SG) 1, including 47 calves in each treatment group, monitored from June 30 to September 9, 2016; and SG2 monitored from August 15 to October 14, 2016, with 50 and 51 calves in covered and control hutches, respectively.

Table 1. Nutrient composition of the calf starter fed to the study calves from d 3 to 60 of life (DM basis)

\begin{tabular}{lc}
\hline Nutrient profile $^{1}$ & Concentration \\
\hline $\mathrm{CP}(\%)$ & 16 \\
Fat (\%) & 2.4 \\
Fiber (\%) & 3.0 \\
$\mathrm{ADF}(\%)$ & 5.0 \\
$\mathrm{Ca}(\%)$ & $0.7-1.2$ \\
$\mathrm{P}(\%)$ & 0.45 \\
$\mathrm{NaCl}(\%)$ & $0.2-0.7$ \\
$\mathrm{Mg}(\%)$ & 0.2 \\
$\mathrm{~K}(\%)$ & 0.9 \\
$\mathrm{Cu}(\mathrm{mg} / \mathrm{kg})$ & 15 \\
$\mathrm{Se}(\mathrm{mg} / \mathrm{kg})$ & 0.3 \\
$\mathrm{Zn}(\mathrm{mg} / \mathrm{kg})$ & 80 \\
$\mathrm{Vitamin} \mathrm{A}(\mathrm{IU} / \mathrm{kg})$ & 1.100 \\
Vitamin D (IU/kg) & 2.200 \\
\hline
\end{tabular}

${ }^{1}$ Guaranteed analysis provided by the manufacturer (Feedex Companies, South Hutchinson, KS).
Holstein heifers were enrolled at $1 \mathrm{~d}$ of life and monitored until $60 \mathrm{~d}$ of age. Calves born from dystocia deliveries (more than light assistance by 1 person required) or with any apparent abnormality were not included. Calves were randomly allocated into 2 housing treatments using polyethylene hutches that were covered by ARC (covered) or hutches left uncovered (control). Aluminized reflective covers (Cool-Calf Covers, Oceanside, CA) were installed according to the manufacturer's directions. Covered hutches had both sidewalls and the roof completely shielded, leaving the back and the front areas of the hutch exposed. Control hutches were not covered at any time. The rear door provided superior airflow for ventilation, and its opaque wall reduced the penetration of UV light. Rear ventilations remained open at all times for both treatments throughout the complete study period. Covered and control hutches were located in contiguous blocks of 25 in 2 parallel lines. Lines were west-east oriented, separated by $5 \mathrm{~m}$, with space of $1.5 \mathrm{~m}$ between hutches. The hutch front door was oriented to the south.

As part of the farm health monitoring program, blood samples were collected from the jugular vein into blood collection tubes without anticoagulant (Becton Dickinson Vacutainer, Franklin Lakes, NJ) between 3 and $7 \mathrm{~d}$ of life for determination of serum total protein (STP) concentrations to evaluate the status of pas- 
sive immune transfer. Samples were allowed to clot and serum was harvested to determine STP concentration using a handheld refractometer. Concentrations of STP were categorized according to their quartile distribution as low $(\leq 6.5 \mathrm{~g} / \mathrm{dL})$; medium $(6.6$ to $7.4 \mathrm{~g} / \mathrm{dL})$; or high $(\geq 7.5 \mathrm{~g} / \mathrm{dL})$ to control for initial immune status and dehydration. Calf weight was measured at $1 \pm 3$ $\mathrm{d}$ and at $60 \pm 3 \mathrm{~d}$ of life using the Weighing Caf-Cart (Raytec LLC, Ephrata, PA).

To facilitate the analysis, time throughout the day was categorized in 3 -h periods as follows: day period (DP) 1 = from 0000 to $0259 \mathrm{~h}$; DP2 = from 0300 to $0559 \mathrm{~h} ; \mathrm{DP} 3=$ from 0600 to $0859 \mathrm{~h} ; \mathrm{DP} 4=$ from 0900 to $1159 \mathrm{~h} ; \mathrm{DP} 5=$ from 1200 to $1459 \mathrm{~h} ; \mathrm{DP} 6=$ from 1500 to 1759 h; DP7 = from 1800 to 2059 h; and DP8 $=$ from 2100 to $2359 \mathrm{~h}$.

\section{Temperature and Humidity Measurements}

Ambient temperature and humidity were measured using 2 HOBO Pro v2 loggers (Onset Computer Corporation, Bourne, MA) set to a sampling rate of 1 reading every $15 \mathrm{~min}$. These loggers were located 3 $\mathrm{m}$ high between the hutch lines. In addition, 4 empty hutches ( 2 per treatment group) were installed between the lines during both study periods ( 8 empty hutches in total) to determine inside hutch temperature and THI. The HOBO UX100-011 temp/RH 2.5\% loggers (Onset Computer Corporation) were installed in the inner surface of the ceiling of the empty hutches, with a sampling rate of 1 reading every $15 \mathrm{~min}$. The THI was calculated for ambient and hutch readings using the equation $\mathrm{THI}=(1.8 \times \mathrm{T}+32)-[(0.55-0.0055 \times \mathrm{RH})$ $\times(1.8 \times \mathrm{T}-26)]$, where $\mathrm{T}=$ temperature $\left({ }^{\circ} \mathrm{C}\right)$ and $\mathrm{RH}$ $=$ relative humidity (Kendall et al., 2008; Vickers et al., 2010). In considering the level of heat stress exposure for the individual across time, days were categorized as presenting low or high THI when THI at DP $5<72$ or $\geq 72$ units, respectively. In a previous report, Carter et al. (2014) suggested the use of 71 and 73 THI units as reference values.

Inner hutch wall and sand bedding temperature were measured consistently at DP5 twice per week in all the hutches housing calves throughout the study, using an IR 1000 infrared thermometer (Klein Tools, Lincolnshire, IL). To measure the temperature of the inner wall, the infrared thermometer was located on the right upper corner of the front door pointing toward the right wall at $30 \mathrm{~cm}$ from the floor. To measure sand temperature, the infrared thermometer was pointed toward the center of the bedding inside the hutch. Sand temperatures were measured on shaded dry areas. Gas ammonia concentrations were screened twice per week in all the hutches housing a calf using the Gas-Alert NH3 logger (BW Technologies, Schaumburg, IL). Ambient and hutch temperature and THI were averaged by 3 -h period, according to the previously described DP classification.

\section{Calf Measurements}

The first outcome measured during farm visits (beginning of DP5) performed twice a week was calf behavior (inside or outside of the hutch). This assessment was performed simultaneously by 2 individuals to minimize the time of evaluation, in the idea of keeping environmental factors consistent. Before assessment, it was ensured that no other activity was performed within $30 \mathrm{~min}$ before the evaluation. Next, health status was assessed using the University of Wisconsin calf health-scoring chart (McGuirk, 2008) for screening of fecal, nasal, eye, and ear abnormalities. Scores were categorized as normal (scores 1 and 2) and abnormal (scores 3 and 4) as presented by Peña et al. (2016). Additionally, clinical dehydration was evaluated based on the score scale proposed by Walker et al. (1998), defined by eye brightness and location and skin elasticity $($ normal $=$ bright eyes and skin tent $<2 \mathrm{~s}$; moderate $=$ skin tent $>2 \mathrm{~s}$ and eye slightly recessed; and severe $=$ skin tent $>10 \mathrm{~s}$ and eye are markedly recessed). Finally, the occurrence of spontaneous coughing during the assessment was also recorded.

Rectal temperature and respiratory rate (breaths/ min) were measured once per week at the beginning of DP6. Rectal temperature was measured using the GLA M700 rectal thermometer (GLA Agricultural Electronics, San Luis Obispo, CA), whereas respiratory rate was measured by counting the movements of the abdominal muscles in the flanks during the respiratory cycle before approaching to the hutch.

\section{Statistical Analysis}

Calf health scores were analyzed using a logistic regression model for repeated measures data (PROC GENMOD, SAS 9.4, SAS Institute Inc., Cary, NC), assuming an exchangeable correlation structure. The model included treatment and rectal temperature. Mortality and culling data were analyzed by use of logistic regression (PROC LOGISTIC), including hutch treatment and SG in the model. Calf rectal temperature and respiratory rate were analyzed using repeated measures (PROC MIXED); the model included treatment, SG, evaluation date, and treatment by evaluation date interaction. Time to event analyses (Kaplan-Meier method) were used to evaluate differences in age at 
the first abnormal health score, at fever presentation, and at clinical dehydration by SG (PROC LIFETEST). The Wilcoxon test was used to determine significant differences between treatment groups for health-related outcomes, and hazard ratios were calculated using Cox proportional hazards models (PROC PHREG).

The analysis of the differences on ADG and weaning weight between treatment groups included the calculation and comparison of least squares means (LSM) using PROC GLM. The model included the treatment, SG, and treatment by SG interaction effects.

The association between calf behavior (inside the hutch at DP5) and treatment was analyzed considering a logistic regression model for repeated measures (PROC GENMOD), assuming an exchangeable correlation structure. The model included treatment and THI category. Analysis of variance (PROC GLM) was used to compare empty hutch temperature and THI between housing treatments for both daily average and DP5 DP6 values. The model included hutch treatment, date of measurement, and the interaction between treatment and date.

Additionally, the performance of the ARC (interior THI, temperature, and relative humidity) was compared with control hutches by DP within SG using PROC GLM. The model included the effects of treatment, DP, SG, and the interaction terms among those effects.

Temperatures in the inner wall and in the bedding sand were analyzed using PROC GLM. To investigate the effect of different levels of ambient THI, the model included ambient THI category measured at DP5. The model included treatment, SG, and THI category, and the treatment by THI category by SG interaction. Statistical significance was defined at $P<0.05$.

\section{RESULTS}

\section{Climatic Data}

A summary of ambient THI, temperature, and relative humidity data are presented in Table 2 for both SG by DP. Overall, temperature, relative humidity, and THI ranged from -1.3 to $38.4^{\circ} \mathrm{C}, 9.8$ to $99.7 \%$, and 33.6 to 81.1 units, respectively. Day period 5 and DP6 had the highest average THI and temperature, and the lowest relative humidity throughout the study. During SG1, there were $68 \mathrm{~d}$ with THI $\geq 72$ units, whereas in SG2 only 33 d had THI $\geq 72$ units.

Table 2. Summary statistics for ambient temperature-humidity index (THI), temperature, and relative humidity by 3-h day period in study group 1 and 2

\begin{tabular}{|c|c|c|c|c|c|c|c|c|c|c|}
\hline $\begin{array}{l}\text { Day } \\
\text { period }^{1}\end{array}$ & Variable & \multicolumn{4}{|c|}{ Study group $1^{2}$} & \multicolumn{4}{|c|}{ Study group 2} & $P$-value ${ }^{3}$ \\
\hline \multirow[t]{2}{*}{1} & THI & 47.3 & 70.2 & 61.3 & 0.2 & 34.2 & 65.7 & 53.3 & 0.2 & $<0.0001$ \\
\hline & Relative humidity & 20.7 & 98.4 & 73.5 & 0.6 & 30.4 & 98.1 & 72.5 & 0.6 & 0.9 \\
\hline \multirow[t]{2}{*}{2} & THI & 44.3 & 68.8 & 58.3 & 0.2 & 33.3 & 65.1 & 50.8 & 0.2 & $<0.0001$ \\
\hline & Temperature & 6.6 & 22.6 & 14.7 & 0.2 & -0.5 & 20.1 & 10.0 & 0.2 & $<0.0001$ \\
\hline \multirow{2}{*}{3} & Temperature & 6.0 & 29.2 & 16.8 & 0.2 & -1.3 & 21.9 & 10.8 & 0.2 & $<0.0001$ \\
\hline & Relative humidity & 23.9 & 99.6 & 75.6 & 0.6 & 34.0 & 99.7 & 78.1 & 0.6 & 0.2 \\
\hline \multirow[t]{3}{*}{4} & THI & 57.4 & 79.6 & 70.4 & 0.2 & 37.2 & 76.6 & 62.6 & 0.2 & $<0.0001$ \\
\hline & Temperature & 14.0 & 34.9 & 24.2 & 0.2 & 2.0 & 32.9 & 18.3 & 0.2 & $<0.0001$ \\
\hline & Relative humidity & 12.4 & 93.7 & 51.3 & 0.6 & 12.4 & 99.7 & 55.8 & 0.6 & $<0.0001$ \\
\hline \multirow[t]{2}{*}{5} & THI & 62.7 & 80.5 & 74.3 & 0.2 & 40.5 & 77.7 & 68.5 & 0.2 & $<0.0001$ \\
\hline & Temperature & 17.5 & 37.3 & 28.9 & 0.2 & 3.9 & 34.3 & 24.1 & 0.2 & $<0.0001$ \\
\hline \multirow{2}{*}{7} & Temperature & 11.5 & 37.5 & 24.4 & 0.2 & 3.3 & 31.4 & 19.5 & 0.2 & $<0.0001$ \\
\hline & Relative humidity & 9.3 & 88.6 & 45.8 & 0.6 & 17.0 & 91.7 & 45.8 & 0.6 & 1.00 \\
\hline \multirow[t]{3}{*}{8} & THI & 51.8 & 76.1 & 65.0 & 0.2 & 36.2 & 70.0 & 57.6 & 0.2 & $<0.0001$ \\
\hline & Temperature & 10.7 & 32.1 & 19.7 & 0.2 & 2.1 & 25.7 & 14.4 & 0.2 & $<0.0001$ \\
\hline & Relative humidity & 14.3 & 95.2 & 62.1 & 0.6 & 21.4 & 96.3 & 62.1 & 0.6 & 1.00 \\
\hline
\end{tabular}

${ }^{1}$ Day period 1 = from 0000 to $0259 \mathrm{~h} ; 2=$ from 0300 to $0559 \mathrm{~h} ; 3=$ from 0600 to $0859 \mathrm{~h} ; 4=$ from 0900 to $1159 \mathrm{~h} ; 5=$ from 1200 to $1459 \mathrm{~h} ; 6$ $=$ from 1500 to $1759 \mathrm{~h} ; 7=$ from 1800 to $2059 \mathrm{~h}$; and $8=$ from 2100 to $2359 \mathrm{~h}$.

${ }^{2}$ Study group 1 was monitored from June 30 to September 9, 2016; study group 2 from August 15 to October 14, 2016.

${ }^{3}$ Statistical significance for the comparison of THI, temperature, and relative humidity LSM between the study groups 1 and 2 within day period. 


\section{Hutch Temperature and THI}

Average temperature in empty hutches during SG1 was higher in covered compared with control hutches $\left(23.2 \pm 0.06\right.$ vs. $\left.22.8 \pm 0.06^{\circ} \mathrm{C}, P<0.0001\right)$. In agreement, THI was also higher in covered hutches $(68.6 \pm$ 0.06 vs. $67.6 \pm 0.06$ units, $P<0.001)$. Likewise, during SG2, average temperature and THI were higher in covered compared with control hutches: $17.1 \pm 0.07$ versus $16.9 \pm 0.07^{\circ} \mathrm{C}(P=0.01)$ and $60.2 \pm 0.08$ versus $59.6 \pm$ 0.08 units $(P<0.001)$, respectively. These differences in temperature and THI were sustained throughout the study period (Figure 2). A summary of hutch temperature, THI, and relative humidity in covered and control empty hutches by DP and SG is presented in Table 3 . Interestingly, when the analyses were restricted to values recorded at DP5 and DP6, the hottest DP during the monitoring period, hutch temperature, and THI did not differ between hutch treatments at SG1 (temperature: $32.0 \pm 0.05$ vs. $32.0 \pm 0.05^{\circ} \mathrm{C}, P=0.7$; THI: 76.8 \pm 0.04 vs. $76.7 \pm 0.05$ units, $P=0.6$ ). In contrast, at SG2 hutch temperature and THI were lower in covered compared with control hutches (temperature: $25.6 \pm$ 0.05 vs. $26.1 \pm 0.05^{\circ} \mathrm{C}, P<0.001$; THI: $69.8 \pm 0.04$ vs. $70.3 \pm 0.04$ units, $P<0.001)$. Covered hutches had significantly higher temperature and THI during DP 1 , $2,3,7$, and 8 in both SG (Table 3 ).

For hutches housing calves, the average inner wall temperature was lower in covered compared with control hutches in both SG (Figure 3a). Overall, covered hutches had a temperature of $24.4 \pm 0.13^{\circ} \mathrm{C}$ versus 25.4 $\pm 0.13^{\circ} \mathrm{C}$ in control hutches $(P<0.0001)$. As expected, in days with ambient THI $\geq 72$ units, the inner wall temperature was significantly higher compared with days with low THI $\left(28.7 \pm 0.11\right.$ vs. $21.1 \pm 0.14^{\circ} \mathrm{C}, P$ $<0.0001)$. In agreement, inner wall temperature was lower in SG2 compared with SG1 (23.9 \pm 0.11 vs. 25.8 $\left.\pm 0.14^{\circ} \mathrm{C}, P<0.0001\right)$.

The triple interaction term between treatment, SG, and THI level was significant $(P<0.0001$; Table 4$)$. Inner wall temperature was lower in covered compared with control hutches when the THI exceeded 72. However, no differences were observed between treatments, or between SG when the ambient THI was lower than
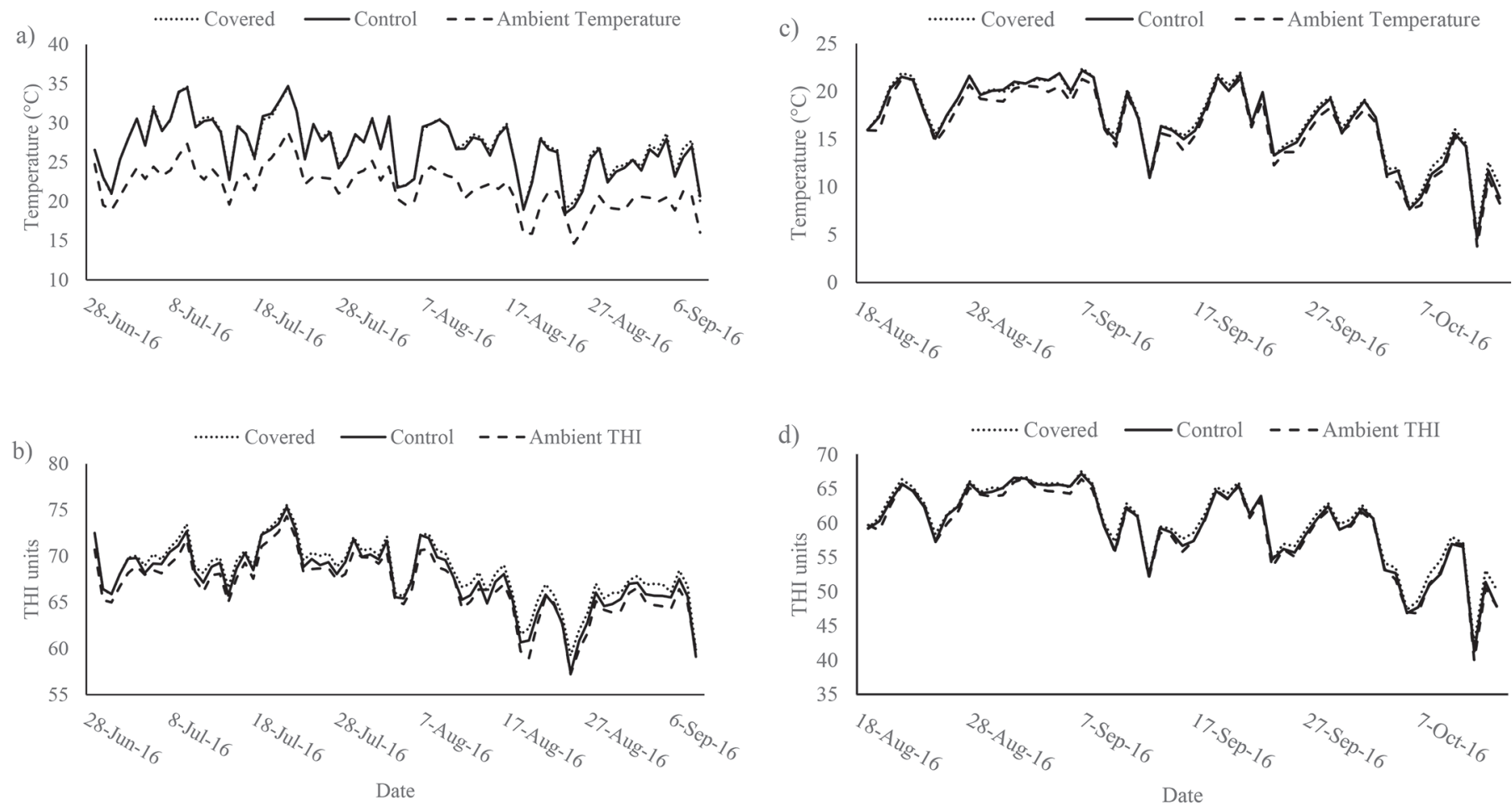

Figure 2. Average daily hutch temperature and temperature-humidity index (THI) in empty hutches. Study group 1: (a) temperature in covered hutches $(\mathrm{n}=2$, dotted line), control hutches $(\mathrm{n}=2$, solid line), and ambient temperature (dashed line); (b) THI in covered hutches ( $\mathrm{n}$ $=2$, dotted line), control hutches $(\mathrm{n}=2$, solid line), and ambient temperature (dashed line). Study group 2: (c) temperature in covered hutches ( $\mathrm{n}=2$, dotted line), control hutches $(\mathrm{n}=2$, solid line), and ambient temperature (dashed line); (d) THI in covered hutches ( $\mathrm{n}=2$, dotted line), control hutches ( $\mathrm{n}=2$, solid line), and ambient temperature (dashed line). Study group 1 was monitored from June 30 to September 9 , 2016; study group 2 from August 15 to October 14, 2016. 
Table 3. Summary of average temperature-humidity index (THI), temperature, and relative humidity measured in covered and control empty hutches allocated within the experimental hutch lines during the study

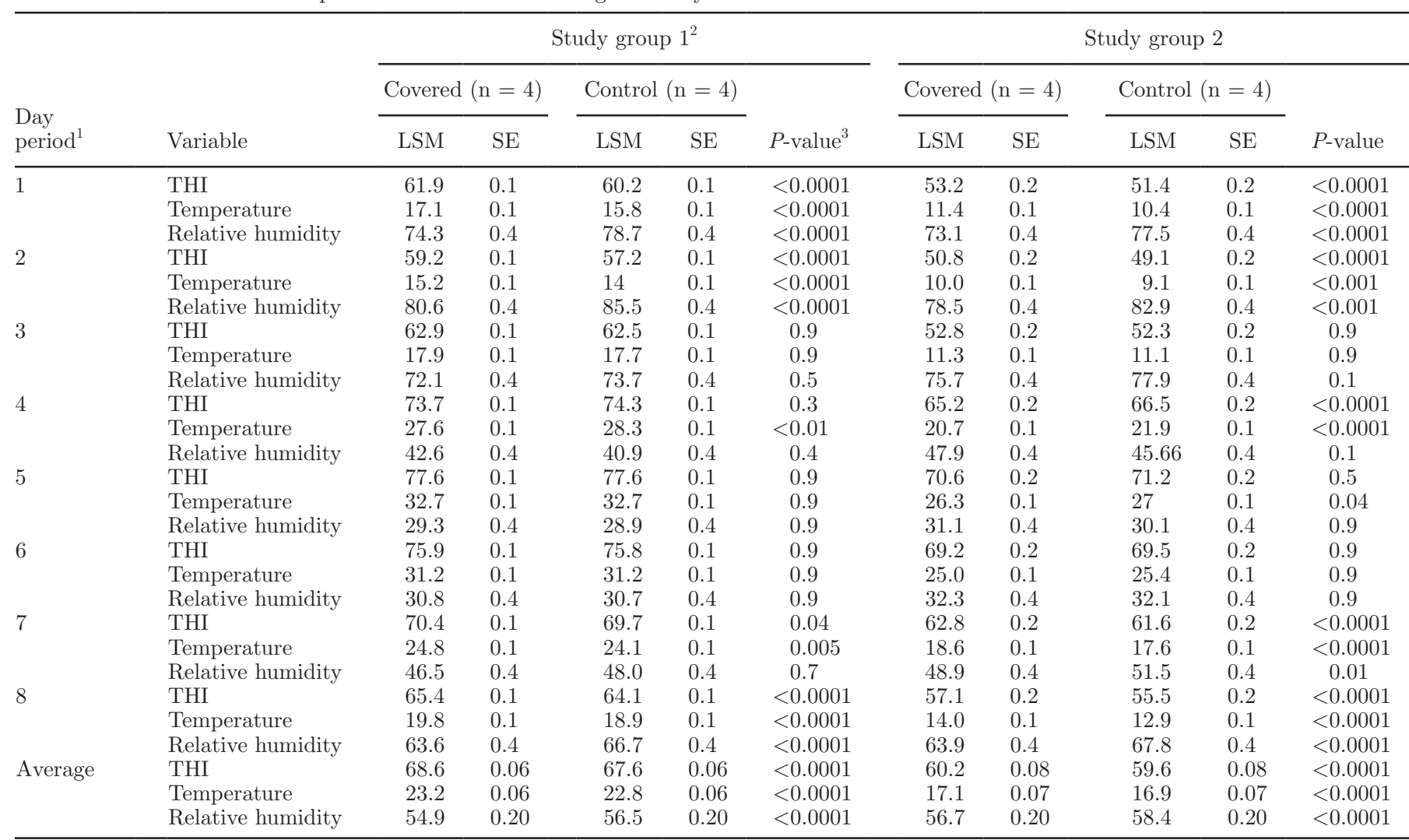

${ }^{1}$ Day period 1 = from 0000 to 0259 h; $2=$ from 0300 to 0559 h; $3=$ from 0600 to 0859 h; 4 = from 0900 to 1159 h; $5=$ from 1200 to 1459 h; 6 $=$ from 1500 to $1759 \mathrm{~h} ; 7=$ from 1800 to $2059 \mathrm{~h}$; and $8=$ from 2100 to $2359 \mathrm{~h}$.

${ }^{2}$ Study group 1 was monitored from June 30 to September 9, 2016; study group 2 from August 15 to October 14, 2016.

${ }^{3}$ Statistical significance for the comparison of THI, temperature, and relative humidity LSM between covered and control hutches within day period and study group.

72 (Table 4). Sand bedding temperature did not differ between covered and control hutches $(21.1 \pm 0.12$ vs. $21.4 \pm 0.12^{\circ} \mathrm{C}, P=0.07$; Figure $3 \mathrm{~b}$ ).

As expected, when ambient daily THI $\geq 72$ units, sand temperature was higher $(24.17 \pm 0.12$ vs. $18.25 \pm$ $\left.0.14^{\circ} \mathrm{C}, P<0.0001\right)$. In agreement, sand temperatures were higher in SG1 compared with SG2 $(21.98 \pm 0.13$ and $\left.20.44 \pm 0.11^{\circ} \mathrm{C}, P<0.0001\right)$. As with the inner wall temperature model, the triple interaction term was significant $(P<0.0001)$. However, no differences were present between covered and control hutches within THI category.

Most of the assessments for gas ammonia indicated concentrations below the detection levels, and consequently no statistical testing was performed.

\section{Calf Health and Performance}

Calves in both treatments and SG had similar STP concentrations (assessed between 3 and $7 \mathrm{~d}$ of life). Sixteen calves died during the study $(\mathrm{ARC}=11$ calves; control $=5$ calves), but no relationship was found between mortality and treatment $(P=0.1)$. Causes for death were bloating $(\mathrm{n}=7)$, respiratory disease $(\mathrm{n}=3)$, diarrhea $(\mathrm{n}=2)$, and undetermined $(\mathrm{n}=$ 4). The odds (95\% CI) of dying were 8.5 (1.7-19.6) times greater for calves in SG1 compared with those in SG2. Sixteen calves that required the use of medical products prohibited in organic certified systems left the farm during the study $(\mathrm{ARC}=10$ calves; control $=$ 6 calves) and no association with the use of ARC ( $P$ $=0.3$ ) was determined. Reasons for leaving the farm included respiratory disease $(72.7 \%)$, diarrhea $(18.2 \%)$, and bloating (9.1\%). No differences in the proportions of calves leaving the farm were determined between SG1 and SG2 $(P=0.09)$.

Results from the logistic regression analyses for health scores are presented in Table 5. Occurrence of diarrhea and housing treatment were associated; the odds $(95 \% \mathrm{CI})$ of presenting diarrhea were 1.30 (1.01-1.60; $P=0.037)$ times greater for calves housed in covered hutches than for those in the control group. 
Table 4. Temperatures of the inner wall and sand bedding at different temperature-humidity index (THI) categories (high: THI $\geq 72$ units, low: THI $<72$ units) measured at day period $5(1200$ to $0259 \mathrm{~h})$ on covered and control hutches housing calves (results are presented by study group)

\begin{tabular}{|c|c|c|c|c|c|c|c|c|c|c|}
\hline \multirow[b]{2}{*}{ Temperature and $\mathrm{THI}^{1}$} & \multicolumn{5}{|c|}{ Study group $1^{2}$} & \multicolumn{5}{|c|}{ Study group 2} \\
\hline & Covered & $\mathrm{SE}$ & Control & $\mathrm{SE}$ & $P$-value & Covered & SE & Control & $\mathrm{SE}$ & $P$-value \\
\hline THI $\geq 72$ & 28.1 & 0.17 & 30.0 & 0.17 & $<0.001$ & 28.0 & 0.27 & 29.2 & 0.21 & 0.029 \\
\hline THI $<72$ & 22.4 & 0.37 & 23.1 & 0.36 & 0.8 & 19.1 & 0.13 & 19.6 & 0.19 & 0.6 \\
\hline \multicolumn{11}{|l|}{ Sand temperature $\left({ }^{\circ} \mathrm{C}\right)$} \\
\hline $\mathrm{THI} \geq 72$ & 23.8 & 0.17 & 24.3 & 0.16 & 0.9 & 24.1 & 0.25 & 24.5 & 0.26 & 0.9 \\
\hline
\end{tabular}

${ }^{1}$ THI determined considering ambient temperature and relative humidity provided by loggers located between the hutch lines.

${ }^{2}$ Study group 1 was monitored from June 30 to September 9, 2016; study group 2 from August 15 to October 14, 2016.
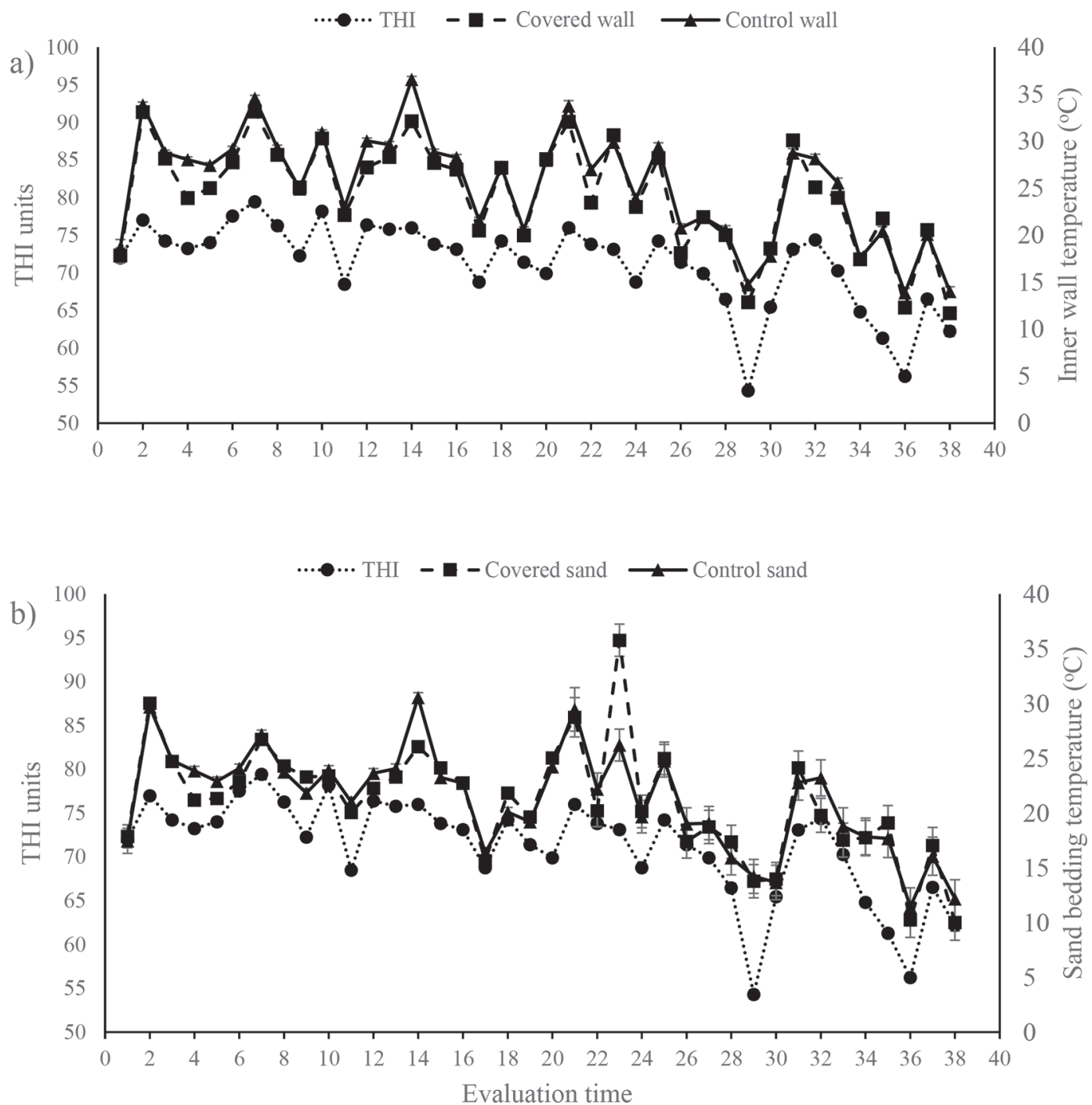

Figure 3. (a) Inner wall temperature in covered (dashed line) or control hutches (solid line) housing calves. (b) Fluctuation of the sand bedding temperature in covered (dashed line) and control hutches (solid line). Ambient temperature-humidity index (THI) at day period 5 (from 1200 to $1459 \mathrm{~h}$ ) is presented with a dotted line. Evaluation times from 1 to 20 and from 21 to 38 consider observations from study group 1 and 2, respectively. Study group 1 was monitored from June 30 to September 9, 2016; study group 2 from August 15 to October 14, 2016. Evaluation points correspond to each assessment performed twice per week. 
Table 5. Odds ratios for health score assessment indicative of health problems for calves housed in covered compared with calves housed in control hutches

\begin{tabular}{lccc}
\hline Health variable & Odds ratio & $95 \% \mathrm{CI}$ & $P$-value \\
\hline Diarrhea $^{1}$ & 1.30 & $1.01-1.60$ & 0.037 \\
Clinical dehydration $^{2}$ & 0.70 & $0.30-1.30$ & 0.20 \\
Nasal $^{3}$ & 1.30 & $1.00-1.80$ & 0.10 \\
Eyes $^{4}$ & 1.46 & $0.90-2.20$ & 0.06 \\
Ears $^{5}$ & 1.40 & $1.03-2.00$ & 0.034 \\
\hline
\end{tabular}

${ }^{1}$ Refers to calves with pasty, loose, and watery feces.

${ }^{2}$ Indicates calves with delayed skin elasticity and dry and recessed eyes.

${ }^{3}$ Consists of calves showing unilateral or bilateral mucus or mucopurulent nasal discharge.

${ }^{4}$ Includes calves with unilateral or bilateral eye discharge or crusty eyes.

${ }^{5}$ Calves presenting unilateral or bilateral droopy ears, head tilt, or both.

Similarly, the odds of an abnormal ear score were 1.40 $(1.03-2.00 ; P=0.034)$ times greater in calves in covered hutches compared with calves in control hutches. No significant associations were found between housing treatment and the occurrence of clinical dehydration, and nasal and eye discharge. As expected, the occurrence of abnormal health scores was associated with high rectal temperature and spontaneous coughing. A 1-unit increase in rectal temperature increased the odds (95\% CI) of diarrhea, clinical dehydration, nasal discharge, eye discharge, and dropped ears by $1.4(1.3-1.6$; $P<0.0001), 1.7$ (1.2-2.2; $P=0.005), 1.3(1.1-1.5 ; P$ $=0.001), 1.2(1.0-1.4 ; P=0.02)$, and $1.5(1.3-1.7$; $P<0.0001)$, respectively. Spontaneous coughing was associated with nasal discharge, increasing the odds of an abnormal nasal score by $1.9(1.3-2.7 ; P=0.001)$ on calves coughing.

Rectal temperatures were not significantly different for calves housed in covered and in control hutches (Figure 4) and the interaction between treatment and evaluation date was not significant. Overall, calves in SG2 had lower average rectal temperatures than those in SG1 $\left(39.2 \pm 0.02\right.$ and $\left.39.1 \pm 0.02^{\circ} \mathrm{C}, P=0.01\right)$. Although this difference is statistically significant, this variation may not be biologically relevant. Similarly, respiratory rates were comparable for calves housed in covered and control hutches $(61 \pm 1$ and $60 \pm 1$ breaths/min) and between SG. However, the repeated measures analyses indicated a significant interaction effect between treatment and date of evaluation $(P=$ 0.04, Figure 5). To perform time-to-event analyses for the first case of an abnormal health score, the data set was divided by SG, as both groups were not contemporaneous in the assessment dates. No differences in the survival functions were determined for diarrhea between treatments in both SG (SG1, $P=0.6$; SG2,
$P=0.2$ ). Regarding time to first diagnosis of nasal abnormalities, only calves in SG2 evidenced significant differences between hutch treatments $(P<0.001)$; the Kaplan-Meier median time was $8 \mathrm{~d}$ versus $22 \mathrm{~d}$ in covered versus control hutches. In agreement, in SG2 the hazard of nasal discharge was 2.1 times greater for calves in covered hutches compared with those in control hutches. No differences between hutch treatments were determined for the time to diagnosis of ear abnormalities, occurrence of fever, or clinical dehydration.

Calf ADG were alike for both hutch treatments within SG (Table 6). Nonetheless, calves in SG2 had significantly greater ADG and weaning weight than calves in SG1 $(1.4 \pm 0.02$ vs. $1.25 \pm 0.01 \mathrm{~kg} / \mathrm{d}, P<$ 0.0001 ; and $80.9 \pm 0.9$ vs. $75.2 \pm 1.03 \mathrm{~kg} / \mathrm{d}, P<0.0001$, respectively). No differences were present in ADG and weaning weight by STP levels.

Overall, the proportions of calves found inside the hutches at DP5 were 64 and $52 \%$ when THI $\geq 72$ and THI $<72$ units, respectively. The logistic regression analysis indicated that treatment and THI category were significantly associated with this behavior $(P=$ 0.03 and $P<0.0001$, respectively). The odds of remaining inside the hutch were $1.33(1.03-1.70)$ times greater for calves housed in control hutches than for those in the covered hutches. Calves evaluated during high THI category had 2.0 (1.67-2.3) times greater odds of remaining inside the hutch than calves exposed to low THI category.

\section{DISCUSSION}

Extreme heat is recognized as an important stressor affecting the welfare and health of dairy cattle. Several strategies regarding housing and cooling have been evaluated (Hill et al., 2011; Binion et al., 2014; Peña et al., 2016), considering disease presentation, performance, rectal temperature, and respiratory rate as indicative parameters of heat stress (Perano et al., 2015; Peña et al., 2016; Nabenishi and Yamazaki, 2017).

The use of polyethylene hutches in calf rearing is widespread in the United States, with approximately 900,000 units in place (Binion et al., 2014). However, high temperature and relative humidity in this type of hutches during summer months have been documented as a potential concern (Hill et al., 2011; Peña et al., 2016).

The use of sunlight reflection technology has recently been proposed to mitigate heat conditions inside polyethylene hutches, and the effect of ARC on interior temperature (Binion et al., 2014; Binion and Friend, 2015), ADG, and calf behavior (Carter et al., 2014) has been evaluated. However, to our knowledge, the effect of ARC use on calf health through the complete 

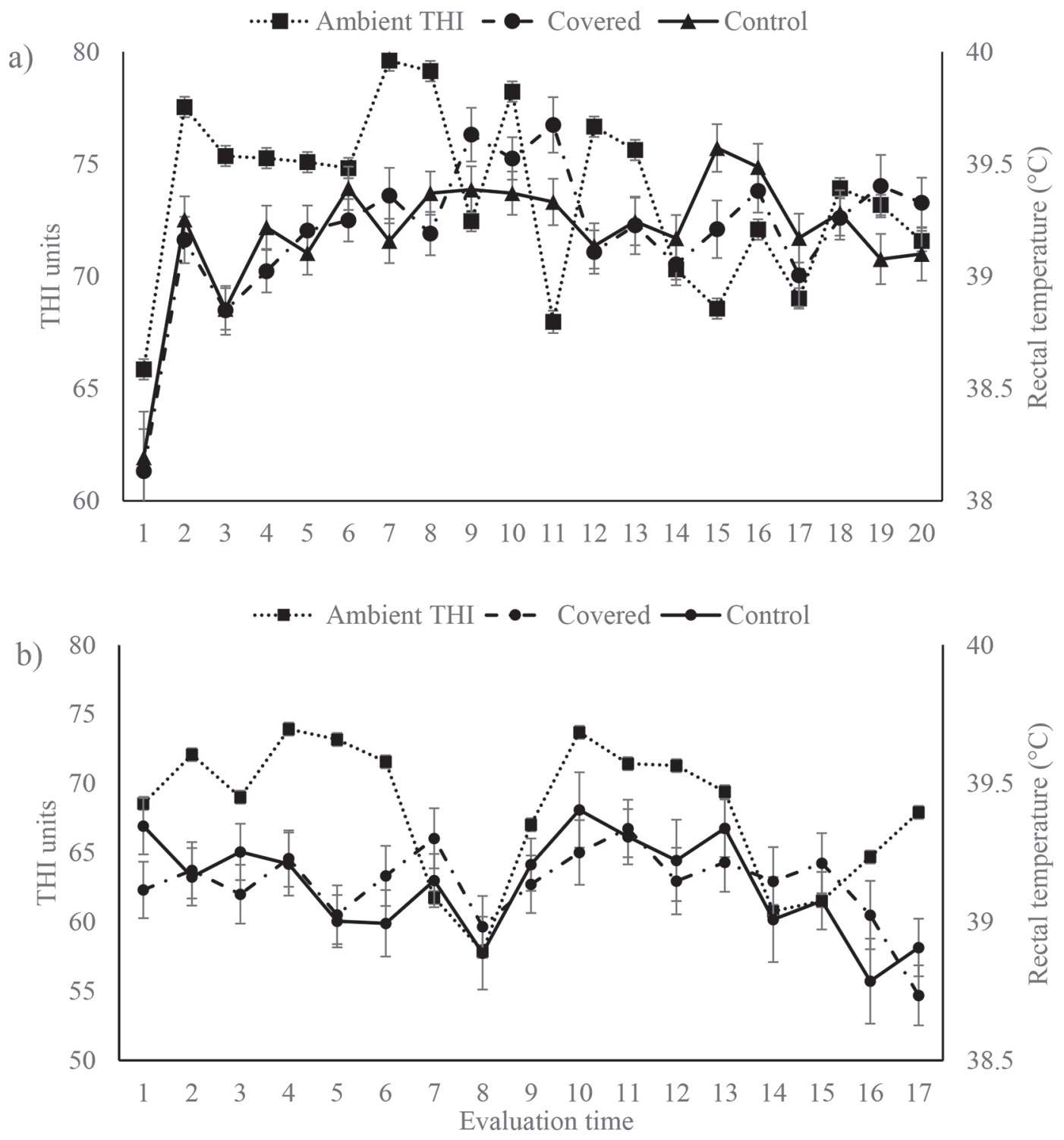

Figure 4. Ambient temperature-humidity index (THI) at day period 6 (from 1500 to $1759 \mathrm{~h}$, dotted line) and rectal temperature (SE) in calves housed in covered (dashed line) or control hutches (solid line) in study groups 1 (a) and 2 (b), during weekly evaluations. Study group 1 was monitored from June 30 to September 9, 2016; study group 2 from August 15 to October 14, 2016. Each evaluation point corresponds to one weekly assessment.

pre-weaning period has not been reported. Our study centered on the occurrence of clinical symptoms present in the main diseases during this phase of calf rearing. Our results indicated associations between housing treatment and some of the health scores evaluated. Contrary to what may be anticipated, the probabilities of abnormal fecal and ear scores were greater in the covered group. Although the magnitude of the odds ratios (Table 5) for the occurrence of abnormal fecal and ear scores does not indicate a strong association between hutch treatment and disease occurrence, these results are in line with greater average temperature and THI found in this group of hutches. The resulting coverage of the openings designed for ventilation on the apex of the roof by the ARC and warmer inside temperatures during some periods of the day (Table 3) could be a potential explanation for this finding.

Calves in both housing treatments were exposed to high air temperatures, which reduces the efficiency of sweating and panting for evaporative cooling (West, 2003). However, calves in SG1 had greater exposure to higher temperatures and THI during longer periods compared with SG2, which could explain their lower health and growth performance.

During the monitoring period, about $70 \%$ of the calves presented at least one abnormal health score, 

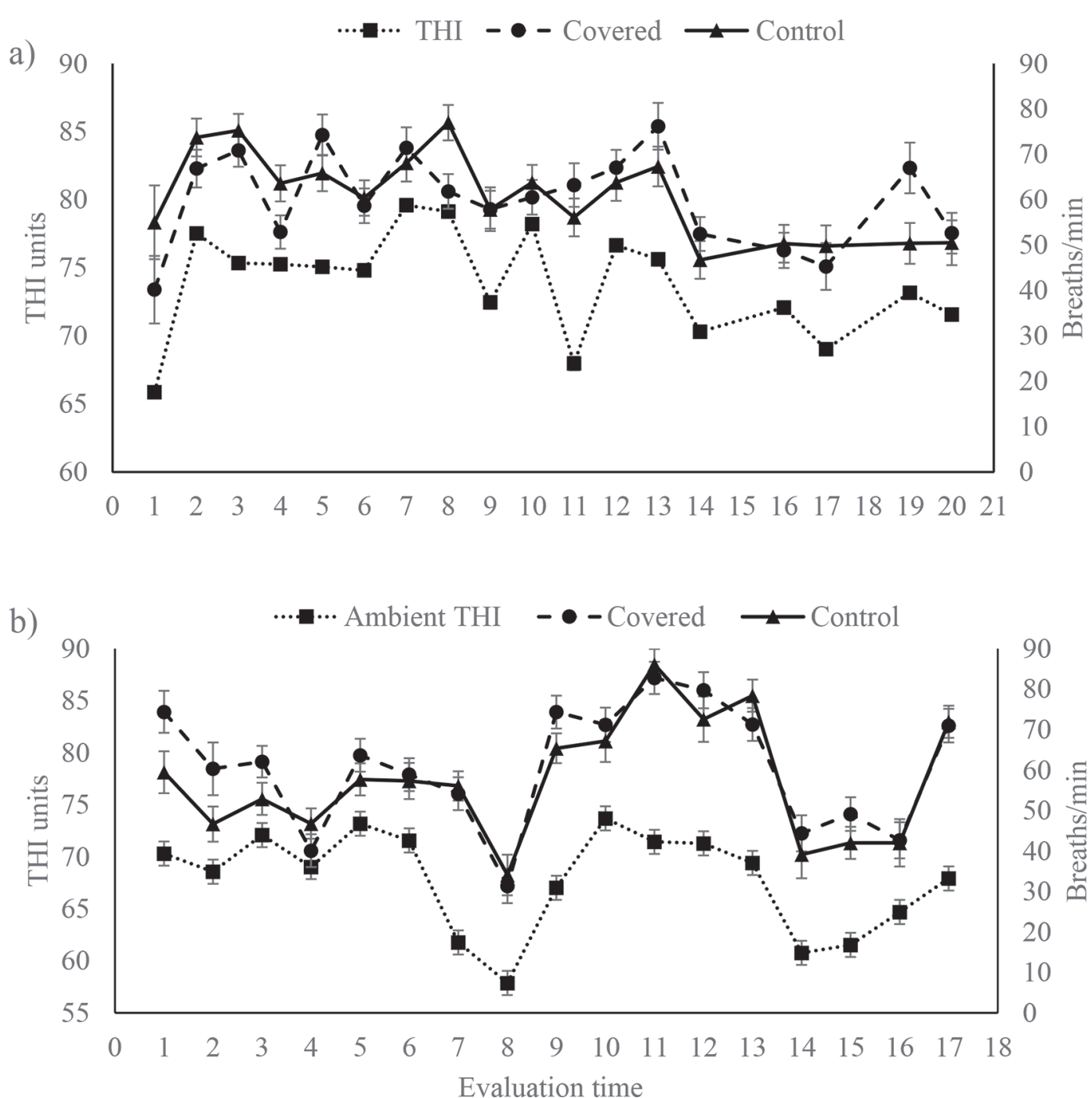

Figure 5. Variation in ambient temperature-humidity index (THI) at day period 6 (from 1500 to 1759 h, dotted line) and respiratory rate in calves housed in covered (dashed line) or control hutches (solid line) in study groups 1 (a) and 2 (b), during weekly evaluations. Study group 1 was monitored from June 30 to September 9, 2016; study group 2 from August 15 to October 14, 2016. Each evaluation point corresponds to one weekly assessment. Vertical bars indicate SE.

Table 6. Least squares means $\pm \mathrm{SE}$ for birth weight, weaning weight, ADG, and serum total protein within the study groups according to treatment (covered vs. control hutches)

\begin{tabular}{|c|c|c|c|c|}
\hline $\begin{array}{l}\text { Study } \\
\text { group }^{1}\end{array}$ & Variable & Covered & Control & $P$-value \\
\hline \multicolumn{5}{|l|}{1} \\
\hline & Birth weight $(\mathrm{kg})$ & $41.5 \pm 0.7$ & $41.5 \pm 0.7$ & 0.9 \\
\hline & Weaning weight $(\mathrm{kg})$ & $77.0 \pm 1.6$ & $73.4 \pm 1.4$ & 0.3 \\
\hline & $\mathrm{ADG}(\mathrm{kg} / \mathrm{d})$ & $0.58 \pm 0.01$ & $0.54 \pm 0.01$ & 0.4 \\
\hline & Serum total protein $(\mathrm{g} / \mathrm{dL})$ & $7.3 \pm 0.1$ & $7.3 \pm 0.1$ & 0.9 \\
\hline 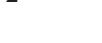 & Birth weight $(\mathrm{kg})$ & $38.8 \pm 0.7$ & $40.2 \pm 0.6$ & 0.2 \\
\hline & Weaning weight $(\mathrm{kg})$ & $80.5 \pm 1.4$ & $81.2 \pm 1.3$ & 0.9 \\
\hline & $\mathrm{ADG}(\mathrm{kg} / \mathrm{d})$ & $0.64 \pm 0.01$ & $0.64 \pm 0.01$ & 0.9 \\
\hline & Serum total protein $(\mathrm{g} / \mathrm{dL})$ & $6.9 \pm 0.1$ & $6.9 \pm 0.1$ & 0.9 \\
\hline
\end{tabular}

${ }^{1}$ Study group 1 was monitored from June 30 to September 9, 2016; study group 2 from August 15 to October $14,2016$. 
reflecting the exposure to challenging environmental conditions in both treatment groups. These values are in the upper range of disease incidence reported in previous studies (Windeyer et al., 2012; Sims et al., 2015; Peña et al., 2016). However, in the current study, calves were systematically assessed for multiple health scores, which may not be comparable to previous reports based on the number of calves that required medical treatment. In addition, although our health assessment followed a well-defined scoring protocol, a current limitation in this and previous studies is the potential for misclassification and inter-evaluator variation. Moreover, due to treatment restrictions associated with organic certification, sick calves showing no signs of significant recovery were submitted to an external calf ranch for conventional treatment.

Hot weather conditions are associated with compromised calf ability to absorb immunoglobulins (West, 2003) and with an affected composition and content of $\mathrm{IgG}$ in the colostrum produced by the dams (Quigley and Drewry, 1998; West, 2003). Calves in this study evidenced adequate levels of STP. However, as hot conditions increase calf dehydration, altering STP concentration, the ability to indirectly predict the success of the passive immunity transfer using this parameter may be reduced. Although it is accepted that STP concentrations $>5.2 \mathrm{~g} / \mathrm{dL}$ indicate adequate IgG concentrations on calves (Windeyer et al., 2014), STP concentrations are not always associated with IgG concentration $>1,000 \mathrm{mg} / \mathrm{dL}$, which is generally considered an adequate concentration (McGuirk and Collins, 2004; Foster et al., 2006). Peña et al. (2016) reported average STP concentrations of $6.05 \pm 0.14 \mathrm{~g} /$ $\mathrm{dL}$ on calves housed in polyethylene hutches; our average STP was $7.1 \pm 0.07 \mathrm{~g} / \mathrm{dL}$. Apparently, both results represent a satisfactory passive immunity transfer. However, in our study, STP levels were not associated with the likelihood of mortality and culling before 60 $\mathrm{d}$ of life, suggesting that baseline values for STP as a measure of immunocompetence may need adjustments that consider environmental conditions that favor the occurrence of dehydration.

Average daily weight gain ranged from 1.2 to $1.4 \mathrm{~kg} / \mathrm{d}$. Calves included in SG2 had significantly greater ADG and weaning weight, which may be in part explained by exposure to milder temperature and THI levels (Tables 2 and 4). However, when the effect of ARC was investigated no differences were found in both SG, which is in agreement with the results from Carter et al. (2014), where ADG assessed in 38 calves housed in reflective insulated hutches did not differ with controls at 32 and $52 \mathrm{~d}$ of life in the Panhandle region of Texas.

Rectal temperatures found in our study were comparable to those reported by Lammers et al. (1996) for calves of similar age during summer in a northern US climate. Throughout the monitoring period, ARC did not affect rectal temperatures at both low $(<72)$ or high $(\geq 72)$ ambient THI. Conversely, other housing treatments have shown significant improvements on rectal temperature. For example, Peña et al. (2016) found that rectal temperatures significantly decreased when calves were placed in wired fence hutches under shade compared with those in polyethylene hutches, when rectal temperature was measured at $1500 \mathrm{~h}$. However, in that study no differences were found when temperature was measured at $0900 \mathrm{~h}$, suggesting that the hottest periods of the day should be considered for the assessment of rectal temperature during summer, as they provide higher exposure to severe ambient conditions. Rectal temperature was associated with the occurrence of diarrhea, clinical dehydration, nasal discharge, eye discharge, and dropped ears, indicating a reliable evaluation of health scores. Similarly, spontaneous coughing was associated with nasal discharge, increasing the odds of an abnormal nasal score by 1.9 (1.3-2.7) on calves coughing. Consequently, their assessment could be considered when the effect of housing strategies on calf health is evaluated.

Respiratory rates are indicated to be more sensitive to ambient THI than body temperature (Berman, 2005). Contrary to other cooling strategies, such as the use of fans, shade, and passive ventilation (West, 2003; Hill et al., 2011; Peña et al., 2016), the use of ARC had no effect reducing this parameter when compared with control hutches, likely due to the inability of the ARC to create a microclimate with significantly lower temperature at time of our evaluation (DP5).

Health, performance, behavior, body temperature, and respiratory rate are influenced by ambient conditions (West, 2003; Roland et al., 2016). Several measures quantifying the effect of ambient conditions on cow performance have been explored (Igono et al., 1992; Bohmanova et al., 2007; Kendall et al., 2008), but few baselines have been documented for pre-weaned dairy calves in the western United States. For cows, THI has been recognized a good estimator for the magnitude of heat stress (West, 2003), where critical values have been stated at 76 units (Igono et al., 1992). Additionally, Bohmanova et al. (2007) established that the range of THI where milk yield declined was 72 to 77 units. For calves, a cut-off value of 77 THI units, under high humidity conditions, has been suggested to investigate the fluctuations of physiologic variables and health responses (Peña et al., 2016). However, some authors have pointed out that values of THI as indicator of heat stress should be adjusted for the climatic conditions of each specific geographic area (Bohmanova et al., 2007). In another report, a THI $\geq 71$ was sig- 
nificantly associated with greater disease incidence on Japanese black calves (Nabenishi and Yamazaki, 2017). In our analyses, a cut-off of 72 units was enough to evidence changes on behavior, respiratory rate, and rectal temperature.

As a positive effect provided by the ARC on calf health and performance would originate from the reduction in temperature and THI inside the hutch, multiple measuring points of temperature in the hutch have been proposed, including hutch inner wall, roof, and the use of radiation balls on the floor (Friend et al., 2014; Binion et al., 2014). In our analyses we included the effect of ambient THI category $(<72 ; \geq 72$ units) at DP5 and DP6 on empty hutch temperature and THI, and on hutch wall temperature in hutches housing calves. Applying ARC lowered inner wall temperature only when ambient THI $\geq 72$ units, which could be attributed to the sunlight reflection exerted by the ARC. Notably, covered empty hutches had higher overall average temperature and THI compared with control hutches. This contradictory finding could relate to the effect of ARC maintaining a higher inside temperature during the night and dawn periods (Table 3), where temperatures were around $0^{\circ} \mathrm{C}$ in some days for both SG (Table 2). This evidence suggests that under conditions comparable to those in this study, the aluminized insulation could be used as a strategy to maintain the inside hutch climate warmer during cooler periods of the day in areas where the ambient conditions fluctuate from low temperatures during night-dawn to high temperatures during sunlight periods.

During hot periods, calves usually seek shade and cooler surfaces to lay down (Roland et al., 2016). In our study, in days with high THI at DP5, a greater proportion of calves remained inside the control hutches compared with the covered hutches. However, this difference on behavior was lost when THI was low. Importantly, the installation of ARC covered the openings in the roof of the polyethylene hutches used in this study, which may have resulted in a significant reduction in ventilation. This is in partial agreement with the findings presented by Carter et al. (2014) that, using a similar setting, reported that the behavior of the calves was influenced by the THI but not by the use of insulation.

The efficacy of ARC on improving hutch interior conditions during the hottest periods of the day (DP5 and DP6) differed for the 2 study periods in this trial. The use of ARC resulted in a significant reduction of empty hutch temperature and THI only during SG2. Nonetheless, this reduction in temperature and THI $\left(0.5^{\circ} \mathrm{C}\right.$ and 0.5 units, respectively) did not have a clear effect on calf health and the physiological variables evaluated in our study.

\section{CONCLUSIONS}

The addition of ARC on polyethylene hutches was effective in reducing the inner hutch wall temperature in hutches housing calves during the hottest periods of the day. On the other hand, the use of covers maintained empty hutches warmer during the coldest periods of day. Our results suggest that the use of ARC did not generate a hutch microclimate that resulted in significant improvements on health and performance of preweaned dairy calves under these specific study settings.

\section{ACKNOWLEDGMENTS}

The authors thank the collaborating dairy farm for allowing us access to their animals and facilities to perform this study. We also thank Fabiola Silva for her assistance throughout the whole study.

\section{REFERENCES}

Armstrong, D. V. 1994. Heat stress interaction with shade and cooling J. Dairy Sci. 77:2044-2050.

Bateman, H. G. 2nd, T. M. Hill, J. M. Aldrich, R. L. Schlotterbeck, and J. L. Firkins. 2012. Meta-analysis of the effect of initial serum protein concentration and empirical prediction model for growth of neonatal Holstein calves through 8 weeks of age. J. Dairy Sci. 95:363-369.

Berman, A. 2005. Estimates of heat stress relief needs for Holstein dairy cows. J. Anim. Sci. 83:1377-1384.

Binion, W. R., and T. H. Friend. 2015. Modeling the effect of reflective calf hutch covers on reducing heat loss. Int. J. Biometeorol. 59:1939-1941.

Binion, W. R., T. H. Friend, and G. A. Holub. 2014. Usefulness of an aluminized polyester film for reducing heat in polyethylene calf hutches. Int. J. Biometeorol. 58:1819-1823.

Bohmanova, J., I. Misztal, and J. B. Cole. 2007. Temperature-humidity indices as indicators of milk production losses due to heat stress. J. Dairy Sci. 90:1947-1956.

Brown, B. M., J. W. Stallings, J. S. Clay, and M. L. Rhoads. 2016 Periconceptional heat stress of Holstein dams is associated with differences in daughter milk production during their first lactation. PLoS One 11:e0148234.

Carroll, J. A., N. C. Burdick, C. C. Chase Jr., S. W. Coleman, and D. E. Spiers. 2012. Influence of environmental temperature on the physiological, endocrine, and immune responses in livestock exposed to a provocative immune challenge. Domest. Anim. Endocrinol. 43:146-153.

Carter, B. H., T. H. Friend, S. M. Garey, J. A. Sawyer, M. B. Alexander, and M. A. Tomazewski. 2014. Efficacy of reflective insulation in reducing heat stress on dairy calves housed in polyethylene calf hutches. Int. J. Biometeorol. 58:51-59.

Colorado Climate Center. 2017. Climate of Colorado. Accessed Mar. 1, 2017. http://climate.colostate.edu/climate_long.html.

Fleenor, W. A., and G. H. Stott. 1980. Hydrometer test for estimation of immunoglobulin concentration in bovine colostrum. J. Dairy Sci. 63:973-977.

Foster, D. M., G. W. Smith, T. R. Sanner, and G. V. Busso. 2006 Serum IgG and total protein concentrations in dairy calves fed two colostrum replacement products. J. Am. Vet. Med. Assoc. 229:1282-1285.

Friend, T. H., J. A. Haberman, and W. R. Binion. 2014. Effect of four different reflective barriers on black-globe temperatures in calf hutches. Int. J. Biometeorol. 58:2165-2168. 
Guo, J. R., A. P. Monteiro, X. S. Weng, B. M. Ahmed, J. Laporta, M. J. Hayen, G. E. Dahl, J. K. Bernard, and S. Tao. 2016. Short communication: Effect of maternal heat stress in late gestation on blood hormones and metabolites of newborn calves. J. Dairy Sci. 99:6804-6807.

Hill, T. M., H. G. Bateman 2nd, J. M. Aldrich, and R. L. Schlotterbeck. 2011. Comparisons of housing, bedding, and cooling options for dairy calves. J. Dairy Sci. 94:2138-2146.

Igono, M. O., G. Bjotvedt, and H. T. Sanford-Crane. 1992. Environmental profile and critical temperature effects on milk production of Holstein cows in desert climate. Int. J. Biometeorol. 36:77-87.

IUPS. 2001. Glossary of terms for thermal physiology. Jpn. J. Physiol. $51: 245-280$.

Johnson, H. D., A. C. Ragsdale, I. L. Berry, and M. D. Shanklin. 1963. Temperature-humidity effects including influence of acclimation in feed and water consumption of Holstein cattle. Missouri Agric. Exp. Sta. Res. Bull. 846. University of Missouri, Columbia.

Kendall, P. E., C. B. Tucker, D. E. Dalley, D. A. Clark, and J. R. Webster. 2008. Milking frequency affects the circadian body temperature rhythm in dairy cows. Livest. Sci. 117:130-138.

Lammers, B. P., J. W. vanKoot, A. J. Heinrichs, and R. E. Graves. 1996. The effect of plywood and polyethylene calf hutches on heat stress. Appl. Eng. Agric. 12:741-745.

McGuirk, S. M. 2008. Disease management of dairy calves and heifers. Vet. Clin. North Am. Food Anim. Pract. 24:139-153.

McGuirk, S. M., and M. Collins. 2004. Managing the production, storage, and delivery of colostrum. Vet. Clin. North Am. Food Anim. Pract. 20:593-603.

Nabenishi, H., and A. Yamazaki. 2017. Effects of temperature-humidity index on health and growth performance in Japanese black calves. Trop. Anim. Health Prod. 49:397-402.

NRC. 2001. Nutrient Requirements of Dairy Cattle. 7th rev. ed. Natl. Acad. Press, Washington, DC.

Peña, G., C. Risco, E. Kunihiro, M. J. Thatcher, and P. J. Pinedo. 2016. Effect of housing type on health and performance of preweaned dairy calves during summer in Florida. J. Dairy Sci. 99:1655-1662.

Perano, K. M., J. G. Usack, L. T. Angenent, and K. G. Gebremedhin. 2015. Production and physiological responses of heat-stressed lactating dairy cattle to conductive cooling. J. Dairy Sci. 98:52525261.

Quigley, J. D. 3rd, and J. J. Drewry. 1998. Nutrient and immunity transfer from cow to calf pre- and postcalving. J. Dairy Sci. 81:2779-2790.

Roland, L., M. Drillich, D. Klein-Jobstl, and M. Iwersen. 2016. Invited review: Influence of climatic conditions on the development, performance, and health of calves. J. Dairy Sci. 99:2438-2452.

Schüller, L. K., I. Michaelis, and W. Heuwieser. 2017. Impact of heat stress on estrus expression and follicle size in estrus under field conditions in dairy cows. Theriogenology 102:48-53.

Sims, L. J., P. J. Pinedo, and G. A. Donovan. 2015. Health and performance of calves fed fresh colostrum from their dams compared to those fed stored colostrum from non-dams. Bov. Pract. 49:13-17.

Spain, J. N., and D. E. Spiers. 1996. Effects of supplemental shade on thermoregulatory response of calves to heat challenge in a hutch environment. J. Dairy Sci. 79:639-646.

Vickers, L. A., O. Burfeind, M. A. von Keyserlingk, D. M. Veira, D. M. Weary, and W. Heuwieser. 2010. Technical note: Comparison of rectal and vaginal temperatures in lactating dairy cows. J. Dairy Sci. 93:5246-5251.

Walker, P. G., P. D. Constable, D. E. Morin, J. K. Drackley, J. H. Foreman, and J. C. Thurmon. 1998. A reliable, practical, and economical protocol for inducing diarrhea and severe dehydration in the neonatal calf. Can. J. Vet. Res. 62:205-213.

West, J. W. 2003. Effects of heat-stress on production in dairy cattle. J. Dairy Sci. 86:2131-2144.

Windeyer, M. C., K. E. Leslie, S. M. Godden, D. C. Hodgins, K. D. Lissemore, and S. J. LeBlanc. 2012. The effects of viral vaccination of dairy heifer calves on the incidence of respiratory disease, mortality, and growth. J. Dairy Sci. 95:6731-6739.

Windeyer, M. C., K. E. Leslie, S. M. Godden, D. C. Hodgins, K. D. Lissemore, and S. J. LeBlanc. 2014. Factors associated with morbidity, mortality, and growth of dairy heifer calves up to 3 months of age. Prev. Vet. Med. 113:231-240.

Yazdi, M. H., H. R. Mirzaei-Alamouti, H. Amanlou, E. Mahjoubi, A. Nabipour, N. Aghaziarati, and L. H. Baumgard. 2016. Effects of heat stress on metabolism, digestibility, and rumen epithelial characteristics in growing Holstein calves. J. Anim. Sci. 94:77-89. 